\title{
ESTADO E POLÍTICAS (PÚBLICAS) SOCIAIS
}

Eloisa de MatTos HöFling*

\begin{abstract}
RESUMO: Para melhor compreensão e avaliação das políticas públicas sociais implementadas por um governo, é fundamental a compreensão da concepção de Estado e de política social que sustentam tais ações e programas de intervenção. Visōes diferentes de sociedade, Estado, política educacional geram projetos diferentes de intervenção nesta área. Este texto objetiva trazer elementos que contribuam para a compreensão desta relação, enfocando autores que se aproximam da abordagem marxista e da neoliberal sobre o tema.
\end{abstract}

Palavras-chave: Estado e política social; Políticas públicas e educação; Política Educacional.

Para além da crescente sofisticação na produção de instrumentos de avaliação de programas, projetos e mesmo de políticas públicas é fundamental se referir às chamadas "questões de fundo", as quais informam, basicamente, as decisões tomadas, as escolhas feitas, os caminhos de implementação traçados e os modelos de avaliação aplicados, em relação a uma estratégia de intervenção governamental qualquer.

E uma destas relaçóes consideradas fundamentais é a que se estabelece entre Estado e políticas sociais, ou melhor, entre a concepção de Estado e a(s) política(s) que este implementa, em uma determinada sociedade, em determinado período histórico.

$\mathrm{Na}$ análise e avaliação de políticas implementadas por um governo, fatores de diferentes natureza e determinação são importantes.

Especialmente quando se focaliza as políticas sociais (usualmente entendidas como as de educação, saúde, previdência, habitação, sanea-

\footnotetext{
* Professora Doutora do Departamento de Metodologia de Ensino (Deme) da Faculdade de Educação da Unicamp. E-mail: amcsl@obelix.unicamp.br
} 
mento etc.) os fatores envolvidos para a aferição de seu "sucesso" ou "fracasso" são complexos, variados, e exigem grande esforço de análise.

Estes diferentes aspectos devem estar sempre referidos a um contorno de Estado no interior do qual eles se movimentam. Torna-se importante aqui ressaltar a diferenciação entre Estado e governo. Para se adotar uma compreensão sintética compatível com os objetivos deste texto, é possível se considerar Estado como o conjunto de instituições permanentes - como órgãos legislativos, tribunais, exército e outras que não formam um bloco monolítico necessariamente - que possibilitam a ação do governo; e Governo, como o conjunto de programas e projetos que parte da sociedade (políticos, técnicos, organismos da sociedade civil e outros) propóe para a sociedade como um todo, configurando-se a orientação política de um determinado governo que assume e desempenha as funções de Estado por um determinado período.

Políticas públicas são aqui entendidas como o "Estado em ação" (Gobert, Muller, 1987); é o Estado implantando um projeto de governo, através de programas, de açóes voltadas para setores específicos da sociedade.

Estado não pode ser reduzido à burocracia pública, aos organismos estatais que conceberiam e implementariam as políticas públicas. As políticas públicas são aqui compreendidas como as de responsabilidade do Estado - quanto à implementação e manutenção a partir de um processo de tomada de decisões que envolve órgãos públicos e diferentes organismos e agentes da sociedade relacionados à política implementada. Neste sentido, políticas públicas não podem ser reduzidas a políticas estatais.

E políticas sociais se referem a ações que determinam o padrão de proteção social implementado pelo Estado, voltadas, em princípio, para a redistribuição dos benefícios sociais visando a diminuição das desigualdades estruturais produzidas pelo desenvolvimento socioeconômico. As políticas sociais têm suas raízes nos movimentos populares do século XIX, voltadas aos conflitos surgidos entre capital e trabalho, no desenvolvimento das primeiras revoluções industriais.

Nestes termos, entendo educação como uma política pública social, uma política pública de corte social, de responsabilidade do Estado - mas não pensada somente por seus organismos.

As políticas sociais - e a educação - se situam no interior de um tipo particular de Estado. São formas de interferência do Estado, visando a manutenção das relações sociais de determinada formação social. 
Portanto, assumem "feiçôes" diferentes em diferentes sociedades e diferentes concepçôes de Estado. É impossível pensar Estado fora de um projeto político e de uma teoria social para a sociedade como um todo.

Pensando em termos concretos, minha reflexão sobre política educacional se insere no contexto do Estado Capitalista, entendido de maneira ampla, sem se considerar definições mais apuradas do que seria este Estado: se democrático liberal, se social democrático etc., etc.

Mais do que definir Estado e suas funções, pretendo focalizar, neste texto, como autores que se inscrevem em tradições diferentes nas ciências sociais analisam o Estado Capitalista e como este pensa e concebe suas políticas sociais - e a política educacional.

Não é uma simples questão de abordagem: concepções metodológicas implicam pressupostos, conceitos, posturas teóricas, sistematizações intelectuais, proposições políticas, enfim, concepções de mundo e sociedade diferentes.

Sem a pretensão de tratar a temática com a profundidade que merece, pretendo focalizar, nos limites deste texto, dois autores que se inscrevem, respectivamente, na tradição ${ }^{1}$ marxista e na liberal, especificamente neoliberal: Claus Offe e Milton Friedman.

Nunca é demais assinalar que o marxismo não pode ser entendido como uma única abordagem, como único tratamento dado a qualquer tema. A tradição marxista desdobra-se num amplo espectro de tendências e mesmo teorias - aliás coerente com seus pressupostos referentes à construção histórica de conceitos. Enraizadas nas clássicas formulações de Marx em relação ao Estado e às ações estatais - as quais estariam, em última instância, voltadas para garantir a produção e reprodução de condições favoráveis à acumulação do capital e ao desenvolvimento do capitalismo -, outras se desdobram na análise da complexa questão da autonomia e possibilidade de ação do Estado capitalista frente às reivindicações e demandas dos trabalhadores e dos setores não beneficiados pelo desenvolvimento capitalista.

Claus Offe, sociólogo alemão, é normalmente considerado um autor moderno no interior da tradição marxista. Ressalto que, relacionada à própria heterogeneidade de sua produção, às posições assumidas em relação a possibilidades e limites das ações do Estado Capitalista contemporâneo, também a "classificação" deste autor é polêmica. $\mathrm{Na}$ medida em que identifico nos textos de Offe a análise do Estado a partir de uma perspectiva de classe, e como uma esfera da sociedade que concentra e manifesta as relações sociais de classe, onde conflitos ocorrem - 
já que no interior do Estado estão presentes interesses referentes à acumulação do capital e às reivindicaçôes dos trabalhadores, quero reforçar a proximidade deste autor à tradição marxista. Compreendo que o autor se insere no debate atual que amplia a dimensão política do Estado para a compreensão de suas funçōes no capitalismo contemporâneo, contribuindo para a ampliação das teorias marxistas tradicionais em relação a Estado e mudanças sociais.

Para a temática aqui abordada, Offe traz interessante contribuição ${ }^{2}$ ao analisar as origens das políticas sociais traçadas pelo Estado Capitalista contemporâneo para a sociedade de classes. Para o autor, o Estado atua como regulador das relações sociais a serviço da manutenção das relações capitalista em seu conjunto, e não especificamente a serviço dos interesses do capital - a despeito de reconhecer a dominação deste nas relaçôes de classe.

Essencialmente voltado para o conteúdo das ações do Estado, Offe tem desenvolvido argumentaçôes na perspectiva de responder as questôes básicas que podem ser assim formuladas: como o Estado capitalista atua para preservar as relaçóes no conjunto da sociedade de classes? Quais as relações de interesses na determinação das ações do Estado? Enfim, como se originam, a partir de que movimentos de interesses surge a política social do Estado capitalista?

No desenvolvimento do processo de acumulação capitalista - e nas crises do capitalismo - as formas de utilização tradicionais da força de trabalho se deterioram, são até mesmo destruídas, escapando à competência das próprios indivíduos a decisão quanto à sua utilização. Relacionado a isto, funçôes tradicionalmente não sujeitas ao controle estatal e circunscritas às esferas privadas da sociedade - inclusive a educação - passam a ser desempenhadas pelo Estado.

Em momentos de profunda assimetria nas relaçóes entre os proprietários de capital e proprietários da força de trabalho, o Estado atua como regulador a serviço da manutenção das relações capitalistas em seu conjunto. E esta função reguladora através da política social é claramente colocada por Offe: "(...) a política social é a forma pela qual o Estado tenta resolver o problema da transformação duradoura de trabalho não assalariado em trabalho assalariado" (Lenhardt \& Offe, 1984, p. 15). O Estado capitalista moderno cuidaria não só de qualificar permanentemente a mão-de-obra para o mercado, como também, através de tal política e programas sociais, procuraria manter sob controle parcelas da população não inseridas no processo produtivo. ${ }^{3}$ 
O sistema de acumulação capitalista engendra em seu desenvolvimento problemas estruturais relativos à constituição e reprodução permanente da força de trabalho e à socialização desta através do trabalho assalariado. O Estado deve "responder" a estes problemas, ou em outros termos, deve assegurar as condições materiais de reprodução da força de trabalho - inclusive visando uma adequação quantitativa entre a força de trabalho ativa e a força de trabalho passiva - e da reprodução da aceitação desta condição.

Estas podem ser consideradas as funções últimas da política social: como as distintas instituições sócio-políticas e estatais contribuem para a resolução dos problemas acima, gerando intervenções do Estado que atingem a sociedade como um todo. E a partir de que referenciais estas ações são equacionadas?

Offe \& Lenhardt colocam em questão dois esquemas de argumentação da ciência política: a) a explicação da gênese da política social estatal baseada na teoria dos interesses e das necessidades, a partir de exigências políticas dos trabalhadores assalariados organizados; b) a explicação da gênese da política social a partir dos imperativos do processo de produção capitalista, das exigências funcionais da produção capitalista (Offe, 1984, p. 32-37).

Ressaltando a dinâmica e movimento próprio do Estado nas sociedades capitalistas modernas, os autores relacionam as origens da política social a um processo de mediação - como estratégia estatal entre interesses conflitivos:

(...) defendemos aqui a tese de que para a explicação da trajetória evolutiva da política social, precisam ser levadas em conta como fatores causais concomitantes tanto exigências quanto necessidades, tanto problemas da integração social quanto problemas da integração sistêmica (Lockwood), tanto a elaboração política de conflitos de classe quanto a elaboração de crises do processo de acumulação. (Offe, op. cit., p. 36)

A concorrência de fatores advindos de diferentes esferas e organismos da sociedade em seu conjunto para a gênese e desenvolvimento do Estado tem sido sistematicamente apontada por Offe em seus trabalhos. Respondendo à uma pergunta sobre um "novo pacto social", o autor assinala:

os problemas de um país não vão ser resolvidos apenas pela ação do Estado ou do mercado. É preciso um novo pacto, que resolve o dever do Estado de dar condições básicas de cidadania, garanta a liberdade do mercado e da competição 
econômica e, para evitar o conflito entre esses dois interesses, permita a influência de entidades comunitárias. (entrevista publicada em Veja, abril de 1998)

Com referência à política educacional, esta complexidade de fatores em seu delineamento é explicitada em texto que discute teoricamente resultados de pesquisas desenvolvidas na perspectiva de se avançar na "análise marxista do Estado" e na "pesquisa política marxista" quanto à discussão sobre a "fundamentação do conceito de Estado Capitalista". Ressaltando que seria equivocado pensar nos objetivos da política educacional voltados estritamente para qualificação da força de trabalho conforme interesses de determinadas indústrias ou de determinadas formas de emprego,

(...) parece ser mais fecundo interpretar a política educacional estatal sob o ponto de vista estratégico de estabelecer um máximo de opçóes de troca para o capital e para a força de trabalho, de modo a maximizar a probabilidade de que membros de ambas as classes possam ingressar nas relações de produção capitalistas. (Offe, 1984, p. 128)

As ações empreendidas pelo Estado não se implementam automaticamente, têm movimento, têm contradições e podem gerar resultados diferentes dos esperados. Especialmente por se voltar para e dizer respeito a grupos diferentes, o impacto das políticas sociais implementadas pelo Estado capitalista sofrem o efeito de interesses diferentes expressos nas relações sociais de poder.

A concepção neoliberal de sociedade e de Estado se inscreve na e retoma a - tradição do liberalismo clássico, dos séculos XVIII e XIX.

Enquanto a obra A riqueza das naçôes: Investigação sobre sua natureza e suas causas, de Adam Smith (publicada em 1776), é identificada como o marco fundamental do liberalismo econômico, $O$ caminho da servidão, de Friedrich Hayek (publicado em 1944), é identificado como o marco do neoliberalismo. As formulações de Milton Friedman, economista da Escola de Chicago, sobre Estado e políticas sociais se identificam estreitamente com as formulações de Hayek.

Por ter desenvolvido de maneira mais explícita formulações sobre políticas sociais - e educação - em seus trabalhos, Friedman será o autor focalizado neste texto como referência à abordagem neoliberal. ${ }^{4}$

Levando-se em consideração a intensa produção e publicações recentes no Brasil sobre neoliberalismo, considero suficiente retomar, para os propósitos deste texto, argumentaçôes destes autores citados que contribuam para a compreensão da natureza da relação entre Estado e política educacional e seus desdobramentos em programas de governo. 
As teorias políticas liberais concebem as funçōes do Estado essencialmente voltadas para a garantia dos direitos individuais, sem interferência nas esferas da vida pública e, especificamente, na esfera econômica da sociedade. Entre os direitos individuais, destacam-se a "propriedade privada como direito natural" (Locke, 1632-1704), assim como o direito à vida, à liberdade e aos bens necessários para conservar ambas. $\mathrm{Na}$ medida em que o Estado, no capitalismo, não institui, não concede a propriedade privada, não tem poder para interferir nela. Tem sim a função de arbitrar - e não de regular - conflitos que possam surgir na sociedade civil, onde proprietários e trabalhadores estabelecem relações de classe, realizam contratos, disputam interesses etc. Estas concepçōes são claramente expressas em colocações fundamentais de Adam Smith em $A$ riqueza das naçôes, voltadas para a crítica ao mercantilismo e às corporaçôes, como:

(...) deixe-se a cada qual, enquanto não violar as leis da justiça, perfeita liberdade de ir em busca de seu próprio interesse, a seu próprio modo, e faça com que tanto seu trabalho como seu capital concorram com os de qualquer outra pessoa ou categoria de pessoas. (p. 47)

(...) Assim é que os interesses e os sentimentos privados dos indivíduos os induzem a converter seu capital para as aplicações que, em casos ordinários, são as mais vantajosas para a sociedade. (p. 104)

As teses neoliberais, absorvendo o movimento e as transformações da história do capitalismo, retomam as teses clássicas do liberalismo e resumem na conhecida expressão "menos Estado e mais mercado" sua concepção de Estado e de governo. Voltadas fundamentalmente para a crítica às teses de Keynes ${ }^{5}$ (1883-1946), que inspiraram o Estado de Bem-Estar Social, defendem enfaticamente as liberdades individuais, criticam a intervenção estatal e elogiam as virtudes reguladoras do mercado. Estas idéias ganharam força e visibilidade com a grande crise do capitalismo na década de 1970 , apresentadas como possíveis saídas para a mesma.

Estas teses podem ser destacadas em trechos do texto referência do neoliberalismo, $O$ caminho da servidão de Hayek:

(...) o respeito pelo homem individual na qualidade de homem, isto é, a aceitação de seus gostos e opiniões como sendo supremos dentro de sua esfera, por mais estritamente que isto se possa circunscrever, e a convicção de que é desejável o desenvolvimento dos dotes e inclinaçôes individuais por parte de cada um. (p. 35) 
O respeito, a promoção e a proteção do indivíduo, dos interesses e das relações que individualmente se estabelecem e se equilibram naturalmente na sociedade também são destacados por Friedman em Capitalismo e liberdade:

(...) os valores de uma sociedade, sua cultura, suas convençôes sociais, todos eles desenvolvem-se de idêntica maneira, através do intercâmbio voluntário, da cooperação espontânea, da evolução de uma estrutura complexa através de tentativas e erros... (p. 68).

Assim, ressaltando os fundamentos do individualismo, os neoliberais defendem a iniciativa individual como base da atividade econômica, justificando o mercado como regulador da riqueza e da renda.

Friedman, especialmente em Capitalismo e liberdade, focaliza o capitalismo competitivo - organizado através de empresas privadas, em regime de livre mercado - como um sistema que exercita a liberdade econômica. Atribui ao Estado o papel de promotor de condiçóes positivas à competitividade individual e aos contratos privados, chamando atenção para os riscos decorrentes da intervenção estatal nas esferas da vida em sociedade:

(...) só há dois meios de coordenar as atividades de milhōes. Um é a direção central, utilizando a coerção - a técnica do Exército e do Estado totalitário moderno. O outro é a cooperação voluntária dos indivíduos - a técnica de mercado. (p. 87)

Para os neoliberais, as políticas (públicas) sociais - ações do Estado na tentativa de regular os desequilíbrios gerados pelo desenvolvimento da acumulação capitalista - são consideradas um dos maiores entraves a este mesmo desenvolvimento e responsáveis, em grande medida, pela crise que atravessa a sociedade. A intervenção do Estado constituiria uma ameaça aos interesses e liberdades individuais, inibindo a livre iniciativa, a concorrência privada, e podendo bloquear os mecanismos que o próprio mercado é capaz de gerar com vistas a restabelecer o seu equilíbrio. Uma vez mais , o livre mercado é apontado pelos neoliberais como o grande equalizador das relações entre os indivíduos e das oportunidades na estrutura ocupacional da sociedade.

Coerentes com estes postulados, os neoliberais não defendem a responsabilidade do Estado em relação ao oferecimento de educação pública a todo cidadão, em termos universalizantes, de maneira padronizada. Um sistema estatal de oferta de escolarização compromete, em última instância, as possibilidades de escolha por parte dos pais em relação 
à educação desejada para seus filhos. Estendendo a lógica do mercado para esta política social, Friedman (1980) assinala que

(...) em escolarização, pais e filhos são os consumidores, e o mestre e o administrador da escola, os produtores. A centralização na escolaridade trouxe unidades maiores, redução da capacidade dos consumidores de escolher e aumento do poder dos produtores.

Para ampliar o escopo de ofertas em relação a orientações e modelos educacionais, e também para aliviar os setores da sociedade que contribuem através de impostos para o sistema público de ensino sem utilizálo necessariamente, as teorias neoliberais propõem que o Estado divida - ou transfira - suas responsabilidades com o setor privado. Assim, além de possibilitar às famílias o direito de livre escolha em relação ao tipo de educação desejada para seus filhos, este seria um caminho para estimular a competição entre os serviços oferecidos no mercado, mantendo-se o padrão da qualidade dos mesmos. A proposta de participação da verba pública para educação - primária e secundária - seria através de "cupons", oferecidos a quem os solicitasse, para "comprar" no mercado os serviços educacionais que mais se identificassem com suas expectativas e necessidades, arcando as famílias com o custo da diferença de preço, caso este seja superior ao cupom recebido.

Para possibilitar este controle maior por parte dos pais e o livre exercício de escolha sobre a educação desejada, a estratégia de descentralização adquire grande importância. A transferência, por parte do Estado, da responsabilidade de execução das políticas sociais às esferas menos amplas, além de contribuir para os objetivos acima, é entendida como uma forma de aumentar a eficiência administrativa e de reduzir os custos.

Nestes termos, coerentes com a defesa e referência essencial aos princípios da liberdade de escolha individual e do livre mercado, os neoliberais postulam para a política educacional ações do Estado descentralizadas, articuladas com a iniciativa privada, a fim de preservar a possibilidade de cada um se colocar, de acordo com seus próprios méritos e possibilidades, em seu lugar adequado na estrutura social.

Após esta sintética exposição das concepções de Estado e educação dos autores acima focalizados, penso ser oportuno ressaltar algumas relações que podem ser estabelecidas entre estes temas.

O processo de definição de políticas públicas para uma sociedade reflete os conflitos de interesses, os arranjos feitos nas esferas de poder que perpassam as instituiçôes do Estado e da sociedade como um todo. 
Um dos elementos importantes deste processo - hoje insistentemente incorporado na análise das políticas públicas - diz respeito aos fatores culturais, àqueles que historicamente vão construindo processos diferenciados de representações, de aceitação, de rejeição, de incorporação das conquistas sociais por parte de determinada sociedade. Com freqüência, localiza-se aí procedente explicação quanto ao sucesso ou fracasso de uma política ou programas elaborados; e também quanto às diferentes soluções e padrão adotados para açôes públicas de intervenção.

A relação entre sociedade e Estado, o grau de distanciamento ou aproximação, as formas de utilização ou não de canais de comunicação entre os diferentes grupos da sociedade e os órgãos públicos - que refletem e incorporam fatores culturais, como acima referidos - estabelecem contornos próprios para as políticas pensadas para uma sociedade. Indiscutivelmente, as formas de organização, o poder de pressão e articulação de diferentes grupos sociais no processo de estabelecimento e reivindicação de demandas são fatores fundamentais na conquista de novos e mais amplos direitos sociais, incorporados ao exercício da cidadania.

Em um Estado de inspiração neoliberal as ações e estratégias sociais governamentais incidem essencialmente em políticas compensatórias, em programas focalizados, voltados àqueles que, em função de sua "capacidade e escolhas individuais", não usufruem do progresso social. Tais ações não têm o poder - e freqüentemente, não se propõem a - de alterar as relações estabelecidas na sociedade.

Pensando em política educacional, ações pontuais voltadas para maior eficiência e eficácia do processo de aprendizagem, da gestão escolar e da aplicação de recursos são insuficientes para caracterizar uma alteração da função política deste setor. Enquanto não se ampliar efetivamente a participação dos envolvidos nas esferas de decisão, de planejamento e de execução da política educacional, estaremos alcançando índices positivos quanto à avaliação dos resultados de programas da política educacional, mas não quanto à avaliação política da educação.

Penso que uma administração pública - informada por uma concepção crítica de Estado - que considere sua função atender a sociedade como um todo, não privilegiando os interesses dos grupos detentores do poder econômico, deve estabelecer como prioritários programas de ação universalizantes, que possibilitem a incorporação de conquistas sociais pelos grupos e setores desfavorecidos, visando à reversão do desequilíbrio social. 
Mais do que oferecer "serviços" sociais - entre eles a educação - as ações públicas, articuladas com as demandas da sociedade, devem se voltar para a construção de direitos sociais.

Numa sociedade extremamente desigual e heterogênea como a brasileira, a política educacional deve desempenhar importante papel ao mesmo tempo em relação à democratização da estrutura ocupacional que se estabeleceu, e à formação do cidadão, do sujeito em termos mais significativos do que torná-lo "competitivo frente à ordem mundial globalizada”.

A frustração - ou não - destas expectativas se coloca em relação direta com os pressupostos e parâmetros adotados pelos órgãos públicos e organismos da sociedade civil com relação ao que se concebe por Estado, Governo e Educação Pública.

\section{Notas}

1. Uso propositadamente esta idéia de estar "inscrito na tradição" por considerar inadequada a classificação precisa de autores no quadro de produção social do conhecimento nas ciências sociais, um processo sempre multifacetado e multidirecional.

2. Utilizo, para estas reflexōes, especialmente os artigos do autor reunidos em: "Problemas estruturais do Estado capitalista" (1984) e "Trabalho e sociedade: Problemas estruturais e perspectivas para com o futuro da sociedade do trabalho" (1991).

3. Para aprofundar esta argumentação e os dois conceitos a ela relacionados - "proletarização passiva" e "proletarização ativa", ver especialmente o texto de Lenhardt \& Offe intitulado "Teoria do Estado e política social; tentativas de explicações político-sociológicas para as funções e os processos inovadores da política social”, p. 10-56 da coletânea de Offe, op. cit.

4. Utilizo para este fim, especialmente os textos de Friedman, Capitalismo e liberdade (1977), e de Hayek, O caminho da servidão (1977).

5. Em sua obra Teoria Geral, de 1936, se refere, entre outros pontos, à presença de um Estado interventor, capaz de instaurar uma base planejada de desenvolvimento, capaz de regular a oferta de investimentos e de emprego ("pleno emprego"), um Estado com ações redistributivistas, inclusive através de altos impostos.

\section{STATE AND SOCIAL (PUBLIC) POLICIES}

ABSTRACT: To better understand and assess the social public policies implemented by a government, one needs to comprehend the conception of State and social policies underlying these actions and intervention programs. In this field, different visions of society, State and educational policy yield different intervention projects. Focusing on the Marxist and neoliberal approaches of the topic, this text seeks to bring forward elements that contribute to understand this relationship.

Key-words: State and social policies; Public policies and education; Educational Policies. 
Referências bibliográficas

FRIEDMAN, Milton. Capitalismo e liberdade. São Paulo: Arte Nova, 1977.

HAYEK, Friedrich. O caminho da servidão. Porto Alegre: Globo, 1977.

OFFE, Claus. Algumas contradiçôes do Estado Social Moderno. Trabalho \& Sociedade: Problemas estruturais e perspectivas para o futuro da sociedade do trabalho, vol. 2, Rio de Janeiro: Tempo Brasileiro, 1991.

OFFE, Claus. Problemas estruturais do Estado capitalista. Rio de Janeiro: Tempo Brasileiro, 1984.

SMITH, Adam. A riqueza das naçōes - investigação sobre sua natureza e suas causas. São Paulo: Abril Cultural, 1983. 